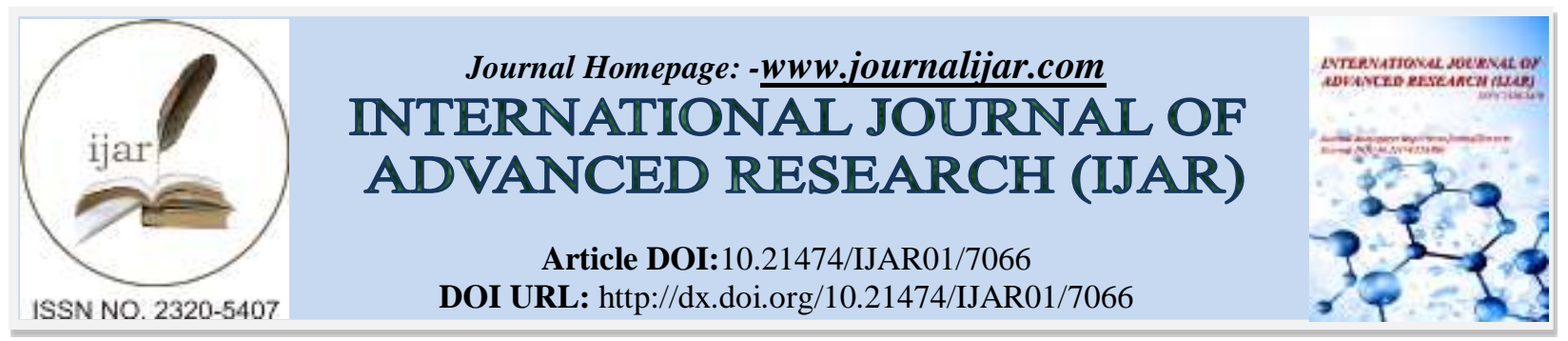

RESEARCH ARTICLE

\title{
GENETIC ANALYSIS OF P53 GENE USING UNWEIGHTED PAIR GROUP METHOD WITH ARITHMETIC MEAN AND NEIGHBOR JOINING METHODS.
}

\section{Auwalu Aliyu $^{1 *}$, Arindam Bhattacharjee ${ }^{1 *}$, Bahman Khalid ${ }^{1}$, Rashmi Pandey ${ }^{1}$, Nayeem Qayoom ${ }^{1}$, Saba $^{1}$, Mohit Kumar ${ }^{1}$, Shobha Mehra ${ }^{1}$, Santosh K. Tiwari ${ }^{2}$, A. Geetha Bhavani ${ }^{4}$, Yugandhar P. Reddy ${ }^{3}$, Varun Kumar Sharma ${ }^{1,2,4}$.}

1. Department of Biotechnology \& Microbiology, School of Sciences, Noida International UniversityNIU, Gautam Budh Nagar 201308, Uttar Pradesh, India.

2. Centre for Liver Research and Diagnostics, Deccan College of Medical Sciences, Kanchanbagh, Hyderabad 500058, Telangana, India.

3. Department of Zoology, The Adoni Arts and Science College, Adoni, Kurnool 518302, Andhra Pradesh, India.

4. NIU Research and Incubation Centre (NRIC), Noida International University-NIU, Gautam Budh Nagar 201308, Uttar Pradesh, India.

\section{Manuscript Info}

Manuscript History

Received: 08 March 2018

Final Accepted: 10 April 2018

Published: May 2018

Keywords:-

p53 gene; phylogenetic analysis; BLAST; MEGA7; UPGMA; Neighbor joining.

\begin{abstract}
The p53 molecular network is a master regulator of cellular process and control various signaling pathway, including cell apoptosis, senescence, cellular growth and DNA repair mechanism. Many species have evolved with unique environmental and genetic responses, we tested the related hypothesis that the evolutionary dynamics of, and mode of selection on, genes within the p53 network differs between human and other species, and that these differences may underlie the evolution of p53 in different species. The sequence of human tumor protein p53 (TP53), mRNA, complete cds sequence was retrieved from the NCBI in FASTA format and was studied for its relationship and percent similarity within human and others species. Variation in p53 gene in human and comparative analysis were studied in detail. The phylogenetic analysis was performed using unweighted pair group method with arithmetic mean (UPGMA) and neighbor joining (NJ) methods and revealed the relationships and percent similarity of Homo sapiens TP53, mRNA, complete cds among different organisms especially with monkey, guinea pig, golden hamster, tupaia, whale, rabbit, pig, cat, sheep and cattle. We observed that positive selection of TP53 gene during the divergence of different species during evolution.
\end{abstract}

Copyright, IJAR, 2018. All rights reserved.

\section{Introduction:-}

Background:-

In the cell development and differentiation, various genes have been identified which play a critical role and control a wide range of cellular process. The p53 is a one of the important proteins which controls cell growth, development, differentiation and cell death. In normal circumstances, expression of p53 is either suppressed or is maintained at basal level. However, activated expression of p53 has been reported in numerous cellular stress such 
as DNA damage, exposure to radiation or chemical, genomic instability and others. The p53 controls the development of cancerous cell and suppresses tumor development which is the basic characteristic of tumor suppressor. p53 was first discovered in 1979 as the main interacting partner of the viral SV40 T-antigen (Chang et al., 1979; Kress et al., 1979; Lane and Crawford, 1979; Linzer and Levine, 1979), and rose to reputation of a tumor suppressor gene in late 1980s (Weisz et al., 2007). Since then, p53 has been one of the most intensively studied proteins worldwide, it is mainly due to the evidence that most of human malignancies bear the abovementioned alterations in its signaling pathway. Indeed, genetic mutations inactivating normal p53 functions can be found in various human tumors, with percentages that vary from nearly $50 \%$ in ovary cancer to $5.8 \%$ in cervical tumors (Bouaoun et al., 2016).

The p53 protein is encoded by the tumor protein p53 (TP53) gene. Its expression is modulated by different physiologic and pathologic stimuli to orchestrate adequate cellular responses in order to maintain genomic stability. p53 is actively involved in multiple signaling pathways and has diverse functional output at cellular level (Chumakov et al., 2007). Studies delving into this relationship between p53 and lifespan have focused on one of the pathways within the multi-pathway p53 signaling network. Additionally, previous observations have demonstrated that mutant p53 with increased activity of the protein can lead to shortened life span and early aging in mice with aging phenotypes such as reduced longevity, osteoporosis, organ atrophy, and reduced stress tolerance (Tyner et al., 2002).

The excessive p53 cell fate decisions can lead to tissue atrophy and degeneration caused by apoptosis and loss of tissue renewal or regeneration caused by senescence. However, it is important to note that mice with super-p53 or, extra copies of p53, display increased tumor suppression without consequence and may live longer (Matheu et al., 2007). Therefore, there is a fine balance between too little p53 and too much p53, and the data on the regulation of the p53 network and aging are equivocal. It has been proposed that since p53 is beneficial at an early age, it can drive aging phenotypes later in life (Campisi 2005). This theory holds optimal as the effects of alleles that are beneficial for an organism early in life can become deleterious at a later stage. Therefore, p53 responses can protect an organism from cancer early in life but can also promote aging phenotypes later. It also indicates that function of p53 could modulated in different species during evolution and divergence of species from same ancestors.

The current study was therefore designed with the following objectives:

1. To understand the evolutionary pattern of p53 gene in various species, including human

2. To identify the evolutionary dynamics and molecular evolution of the genes contained within the p53 network.

We performed this analysis by generating comparative transcriptomes across various species, and by comparing pathway evolution between different species of mammals and others. We also examined genes in the pathway individually and the pathway as a whole using a large multi-gene dataset. We queried the sequences for signatures of selection - both purifying and positive, to determine if the ancestral species branch and whether the entire species clade experienced different rates and forms of evolutionary history between the species. Additionally, the evolution of the p53 network in human was examined and we compared it to other human as well as other species because p53 network signaling also has implications in broad range of cellular functions.

\section{Materials and Methods:-}

Sequence retrieval:-

Homo sapiens TP53, mRNA, complete coding sequence (cds) sequence (AB082923.1) was retrieved from the National Center for Biotechnology Information (NCBI; http://www.ncbi.nlm.nih.gov) databases in FASTA format.

\section{Local sequence alignment:-}

Basic local Alignment Search Tool (BLAST) was performed for the Homo sapiens TP53, mRNA, complete cds sequence retrieved from NCBI to identify its relatives in different organisms including human using the online NCBI-BLAST (https://blast.ncbi.nlm.nih.gov/Blast.cgi). This software takes the data in FASTA format and produces the BLAST table.

\section{Phylogenetic analysis:-}

Phylogenetic analysis of Homo sapiens TP53, mRNA, complete cds sequence through UPGMA and Neighbor Joining (NJ) were carried out using MEGA7 software (Kumar et al., 2016). Phylogenetic trees were constructed by the software showing the ancestral relationship among the sequences. The UPGMA phylogeny tree give different 
GTACGTGCTTTCCACGACGGTGACACGCTTCCCTGGATTGGCCAGACTGCCTTCCGGGTCACTGCCATG GAGGAGCCGCAGTCAGATCCTAGCGTCGAGCCCCCTCTGAGTCAGGAAACATTTTCAGACCTATGGAA ACTACTTCCTGAAAACAACGTTCTGTCCCCCTTGCCGTCCCAAGCAATGGATGATTTGATGCTGTCCCC GGACGATATTGAACAATGGTTCACTGAAGACCCAGGTCCAGATGAAGCTCCCAGAATGCCAGAGGCT GCTCCCCGCGTGGCCCCTGCACCAGCAGCTCCTACACCGGCGGCCCCTGCACCAGCCCCCTCCTGGCC CCTGTCATCTTCTGTCCCTTCCCAGAAAACCTACCAGGGCAGCTACGGTTTCCGTCTGGGCTTCTTGCA TTCTGGGACAGCCAAGTCTGTGACTTGCACGTAVCTCCCCTGCCCTCAACAAGATGTTTTGCCAACTGG CCAAGACCTGCCCTGTGCAGCTGTGGGTTGATTCCACACCCCCGCCCGGCACCCGCGTCCGCGCCATG GCCATCTACAAGCAGTCACAGCACATGACGGAGGTTGTGAGGCGCTGCCCCCACCATGAGCGCTGCTC AGATAGCGATGGTCTGGCCCCTCCTCAGCATCTTATCCGAGTGGAAGGAAATTTGCGTGTGGAGTATT TGGATGACAGAAACACTTTTCGACATAGTGTGGTGGTGCCCTATGAGCCGCCTGAGGTTGGCTCTGAC TGTACCACCATCCACTACAACTACATGTGTAACAGTTCCTGCATGGGCGGCATGAACCGGAGGCCCAT CCTCACCATCATCACACTGGAAGACTCCAGTGGTAATCTACTGGGACGGAACAGCTTTGAGGTGCATG TTTGTGCCTGTCCTGGGAGAGACCGGCGCACAGAGGAAGAGAATCTCCGCAAGAAAGGGGAGCCTCA CCACGAGCTGCCCCCAGGGAGCACTAAGCGAGCACTGTCCAACAACACCAGCTCCTCTCCCCAGCCAA AGAAGAAACCACTGGATGGAGAATATTTCACCCTTCAGATCCGTGGGCGTGAGCGCTTCGAGATGTTC CGAGAGCTGAATGAGGCCTTGGAACTCAAGGATGCCCAGGCTGGGAAGGAGCCAGGGGGGAGCAGG

clusters showing their evolution relationship with each other and NJ tree reveals different clade showing their evolutionary distance within different species. The sequences which lie in the same cluster are closely related. 
GCTCACTCCAGCCACCTGAAGTCCAAAAAGGGTCAGTCTACCTCCCGCCATAAAAAACTCATGTTCAA GACAGAAGGGCCTGACTCAGACTGACATTCTCCACTTCTTGTTCCCCACTGACAGCCTCCCACCCCCAT СTCTCCСTCCCСTGCCATTTTGGGTTTTGGGTCTTTGAACCCTTGCTTGCAATAGGTGTGCGTCAGAAGC ACCCAGGACTTCCATTTGCTTTGTCCCGGGGCTCCACTGAACAAGTTGGCCTGCACTGGTGTTTTGTTG TGGGGAGGAGGATGGGGAGTAGGACATACCAGCTTAGATTTTAAGGTTTTTACTGTGAGGGATGTTTG GGAGATGTAAGAAATGTTCTTGCAGTTAAGGGTTAGTTTACAATCAGCCACATTCTAGGTAGGGGCCC ACTTCACCGTACTAACCAGGGAAGCTGTCCCTCACTGTTGAATTTTCTCTAACTTCAAGGCCCATATCT GTGAAATGCTGGCATTTGCACCTACCTCACAGAGTGCATTGTGAGGGTTAATGAAATAATGTACATCT GGCCTTGAAACCACCTTTTATTACATGGGGTCTAGAACTTGACCCCCTTGAGGGTGCTTGTTCCCTCTC CCTGTTGGTCGGTGGGTTGGTAGTTTCTACAGTTGGGCAGCTGGTTAGGTAGAGGGAGTTGTCAAGTCT CTGCTGGCCCAGCCAAACCCTGTCTGACAACCTCTTGGTGAACCTTAGTACCTAAAAGGAAATCTCAC CCCATCCCACACCCTGGAGGATTTCATCTCTTGTATATGATGATCTGGATCCACCAAGACTTGTTTTAT GCTCAGGGTCAATTTCTTTTTTCTTTTTTTTTTTTTTTTTCTTTTTCTTTGAGACTGGGTCTCGCTTTGTTG CCCAGGCTGGAGTGGAGTGGCGTGATCTTGGCTTACTGCAGCCTTTGCCTCCCCGGCTCGAGCAGTCCT GCCTCAGCCTCCGGAGTAGCTGGGACCACAGGTTCATGCCACCATGGCCAGCCAACTTTTGCATGTTTT GTAGAGATGGGGTCTCACAGTGTTGCCCAGGCTGGTCTCAAACTCCTGGGCTCAGGCGATCCACCTGT CTCAGCCTCCCAGAGTGCTGGGATTACAATTGTGAGCCACCACGTCCAGCTGGAAGGGTCAACATCTT TTACATTCTGCAAGCACATCTGCATTTTCACCCCACCCTTCCCCTCCTTCTCCCTTTTTATATCCCATTTT TATATCGATCTCTTATTTTACAATAAAACTTTGCTGCCAAAAAAAAAAAAAAAAAAA

Table 1:-Homo sapiens TP53, mRNA, complete cds (AB082923.1) mRNA, messenger ribonucleic acid

Table 2:-BLAST table of Human p53

\begin{tabular}{|c|c|c|c|c|c|c|}
\hline $\begin{array}{l}\text { S. } \\
\text { No. }\end{array}$ & $\begin{array}{l}\text { Accession } \\
\text { number }\end{array}$ & e-Value & Organism & Description & $\begin{array}{l}\text { Sequence } \\
\text { length }\end{array}$ & $\begin{array}{l}\% \text { pair } \\
\text { wise }\end{array}$ \\
\hline 1 & AB082923.1 & 0.0 & Homo sapiens & $\begin{array}{l}\text { Homo sapiens tumor protein p53, } \\
\text { mRNA, complete cds }\end{array}$ & 4527 & $100 \%$ \\
\hline 2 & BC003596.1 & 0.0 & Homo sapiens & $\begin{array}{l}\text { Homo sapiens mRNA for p53, } \\
\text { complete cds }\end{array}$ & 4495 & $99 \%$ \\
\hline 3 & AF307851.1 & 0.0 & Homo sapiens & $\begin{array}{l}\text { Homo sapiens p53 protein mRNA, } \\
\text { complete cds }\end{array}$ & 4492 & $99 \%$ \\
\hline 4 & $\begin{array}{l}\text { NM } \\
001126112.2\end{array}$ & 0.0 & Homo sapiens & $\begin{array}{l}\text { Homo sapiens tumor protein p53, } \\
\text { transcript variant } 2, \text { mRNA }\end{array}$ & 4470 & $99 \%$ \\
\hline 5 & HG975427.1 & 0.0 & Homo sapiens & $\begin{array}{l}\text { Homo sapiens processed transcript } \\
\text { p53-mRNA }\end{array}$ & 4457 & $99 \%$ \\
\hline 6 & NM 000546.5 & 0.0 & Homo sapiens & $\begin{array}{l}\text { Homo sapiens tumor protein p53, } \\
\text { transcript variant } 1, \text { mRNA }\end{array}$ & 4457 & $99 \%$ \\
\hline 7 & DQ191317.1 & 0.0 & Homo sapiens & $\begin{array}{l}\text { Homo sapiens p53 protein mRNA, } \\
\text { complete cds, alternatively spliced }\end{array}$ & 4353 & $99 \%$ \\
\hline 8 & DQ191317.1 & 0.0 & Homo sapiens & $\begin{array}{l}\text { Homo sapiens p53 protein mRNA, } \\
\text { complete cds, alternative spliced }\end{array}$ & 4353 & $99 \%$ \\
\hline 9 & FJ207420.1 & 0.0 & Homo sapiens & $\begin{array}{l}\text { Homo sapiens mutant p53 mRNA, } \\
\text { complete cds }\end{array}$ & 4348 & $99 \%$ \\
\hline 10 & X01405.1 & 0.0 & Human & $\begin{array}{l}\text { Human mRNA fragment for } \\
\text { phosphoprotein p53 }\end{array}$ & 3740 & $99 \%$ \\
\hline 11 & $\begin{array}{l}\text { NM } \\
001126115.1\end{array}$ & 0.0 & Homo sapiens & $\begin{array}{l}\text { Homo sapiens tumor protein p53, } \\
\text { transcript variant } 5 \text {, mRNA }\end{array}$ & 3668 & $99 \%$ \\
\hline 12 & DQ186650.1 & 0.0 & Homo sapiens & $\begin{array}{l}\text { Homo sapiens del } 133 \text { isoform } \\
\text { mRNA, complete cds }\end{array}$ & 3559 & $99 \%$ \\
\hline 13 & JN900492.1 & 0.0 & Homo sapiens & $\begin{array}{l}\text { Homo sapiens tumor suppressor } \\
\text { TP53 mRNA, complete cds, } \\
\text { alternative spliced }\end{array}$ & 4456 & $99 \%$ \\
\hline 14 & $\begin{array}{l}\text { NM } \\
\text { 001126118.1 }\end{array}$ & 0.0 & Homo sapiens & $\begin{array}{l}\text { Homo sapiens tumor protein p53, } \\
\text { transcript variant } 8, \text { mRNA }\end{array}$ & 4456 & $99 \%$ \\
\hline 15 & $\begin{array}{l}\text { NM } \\
\text { 001126116.I }\end{array}$ & 0.0 & Homo sapiens & $\begin{array}{l}\text { Homo sapiens tumor protein p53, } \\
\text { transcript variant } 6, \text { mRNA }\end{array}$ & 3669 & $99 \%$ \\
\hline
\end{tabular}




\begin{tabular}{|c|c|c|c|c|c|c|}
\hline 16 & AK297462.1 & $\mathbf{0 . 0}$ & Homo sapiens & $\begin{array}{l}\text { Homo sapiens cDNA FLJ54297 } \\
\text { complete cds, highly similar to } \\
\text { cellular tumor antigen p53 }\end{array}$ & 2914 & $99 \%$ \\
\hline 17 & DQ186649.1 & 0.0 & Homo sapiens & $\begin{array}{l}\text { Homo sapiens p53 gamma isoform } \\
\text { mRNA, complete cds }\end{array}$ & 4356 & $98 \%$ \\
\hline 18 & DQ186648.1 & 0.0 & Homo sapiens & $\begin{array}{l}\text { Homo sapiens beta isoform mRNA, } \\
\text { complete cds }\end{array}$ & 4352 & $98 \%$ \\
\hline 19 & DQ186652.1 & 0.0 & Homo sapiens & $\begin{array}{l}\text { Homo sapiens del } 133 \text { p53 gamma } \\
\text { isoform mRNA, complete cds }\end{array}$ & 3564 & $98 \%$ \\
\hline 20 & DQ186651.1 & 0.0 & Homo sapiens & $\begin{array}{l}\text { Homo sapiens del } 133 \text { p53 beta } \\
\text { isoform mRNA, complete cds. }\end{array}$ & 3560 & $98 \%$ \\
\hline 21 & AK225838.1 & 0.0 & Homo sapiens & $\begin{array}{l}\text { Homo sapiens mRNA for cellular } \\
\text { tumor antigen p53 variant, clone: } \\
\text { FCC127A11 }\end{array}$ & 2811 & 99\% \\
\hline 22 & AK223026.1 & 0.0 & Homo sapiens & $\begin{array}{l}\text { Homo sapiens } \text { mRNA for tumor } \\
\text { protein p53 variant, clone: } \\
\text { JTH07296 }\end{array}$ & 3086 & $99 \%$ \\
\hline 23 & K03199.1 & $\mathbf{0 . 0}$ & Human & $\begin{array}{l}\text { Human p53 cellular tumor antigen } \\
\text { mRNA, complete cds }\end{array}$ & 2939 & $99 \%$ \\
\hline 24 & NG 017013.2 & 0.0 & Homo sapiens & $\begin{array}{l}\text { Homo sapiens tumor protein p53, } \\
\text { RefSeqGene on chromosome }\end{array}$ & 4478 & $99 \%$ \\
\hline 25 & AC007421.13 & $\mathbf{0 . 0}$ & Homo sapiens & $\begin{array}{l}\text { Homo sapiens chromosome 17, } \\
\text { clone RP5-1030O14, complete } \\
\text { sequence }\end{array}$ & 2754 & $99 \%$ \\
\hline 26 & AY838896.1 & $\mathbf{0 . 0}$ & Homo sapiens & $\begin{array}{l}\text { Homo sapiens tumor protein p53, } \\
\text { complete cds }\end{array}$ & 4483 & $99 \%$ \\
\hline 27 & AC087388.9 & 0.0 & Homo sapiens & $\begin{array}{l}\text { Homo sapiens chromosome 17, } \\
\text { clone RP11-199F11, complete } \\
\text { sequence }\end{array}$ & 4772 & $99 \%$ \\
\hline 28 & JQ694049.1 & $\mathbf{0 . 0}$ & Homo sapiens & $\begin{array}{l}\text { Homo sapiens isolate Ipch358_Col1 } \\
\text { tumor suppressor p53 mRNA, } \\
\text { complete cds }\end{array}$ & 2329 & $99 \%$ \\
\hline 29 & JQ694051.1 & 0.0 & Homo sapiens & $\begin{array}{l}\text { Homo sapiens isolate Ipch358_Col } \\
11 \text { tumor suppressor p53 mRNA } \\
\text { complete cds }\end{array}$ & 2326 & $99 \%$ \\
\hline 30 & AK312568.1 & 0.0 & Homo sapiens & $\begin{array}{l}\text { Homo sapiens cDNA, FLJ92943, } \\
\text { Homo sapiens tumor protein p53, } \\
\text { mRNA }\end{array}$ & 2268 & $99 \%$ \\
\hline 31 & X02469.1 & $\mathbf{0 . 0}$ & Human & $\begin{array}{l}\text { Human mRNA for p53 cellular } \\
\text { tumor antigen }\end{array}$ & 2268 & $99 \%$ \\
\hline 32 & U48957.1 & 0.0 & $\begin{array}{l}\text { Macaca } \\
\text { fascicularis }\end{array}$ & $\begin{array}{l}\text { Macaca fascicularis p53 gene, } \\
\text { complete cds }\end{array}$ & 1929 & $96 \%$ \\
\hline 33 & U48956.1 & 0.0 & $\begin{array}{l}\text { Macaca } \\
\text { mulatta }\end{array}$ & $\begin{array}{l}\text { Macaca mulatta p53 gene, complete } \\
\text { cds }\end{array}$ & 1945 & $96 \%$ \\
\hline 34 & AF456343.1 & 0.0 & $\begin{array}{l}\text { Macaca } \\
\text { fascicularis }\end{array}$ & $\begin{array}{l}\text { Macaca fascicularis tumor protein } \\
\text { p53 (TP53), mRNA }\end{array}$ & 1951 & $96 \%$ \\
\hline 36 & AF175893.1 & 0.0 & $\begin{array}{l}\text { Tupaia } \\
\text { belangeri }\end{array}$ & $\begin{array}{l}\text { Tupaia belangeri chinensis p53 } \\
\text { tumor suppressor protein (p53) } \\
\text { mRNA, complete cds }\end{array}$ & 1616 & $91 \%$ \\
\hline 37 & FJ855223.1 & 0.0 & Ovis aries & $\begin{array}{l}\text { Ovis aries tumor protein } \mathrm{p53} \\
\text { mRNA }\end{array}$ & 1075 & $87 \%$ \\
\hline 38 & AF124298.2 & $\mathbf{0 . 0}$ & Sus sacrofa & $\begin{array}{l}\text { Sus sacrofa protein mRNA, partial } \\
\text { cds }\end{array}$ & 1064 & $87 \%$ \\
\hline 39 & X81704.1 & 0.0 & Bos taurus & Bos taurus p53 mRNA & 1059 & $87 \%$ \\
\hline 40 & D49825.1 & $\mathbf{0 . 0}$ & Bos & Bos primigenius p53 mRNA, partial & 1068 & $87 \%$ \\
\hline
\end{tabular}




\begin{tabular}{|c|c|c|c|c|c|c|}
\hline & & & primigenius & cds & & \\
\hline 41 & AF475081.1 & $\mathbf{0 . 0}$ & $\begin{array}{l}\text { Delphinapterus } \\
\text { leucas }\end{array}$ & $\begin{array}{l}\text { Delphinapterus leucas p53 mRNA, } \\
\text { complete cds }\end{array}$ & 1275 & $86 \%$ \\
\hline 42 & $\begin{array}{l}\text { NM } \\
00108240.1\end{array}$ & 0.0 & $\begin{array}{l}\text { Oryctolagus } \\
\text { cuniculu }\end{array}$ & $\begin{array}{l}\text { Oryctolagus cuniculus tumor } \\
\text { protein p53, mRNA }\end{array}$ & 1310 & $83 \%$ \\
\hline 43 & NM_174201.2 & 0.0 & Bos taurus & $\begin{array}{l}\text { Bos indicus tumor protein p53 } \\
\text { (TP53), mRNA }\end{array}$ & 1109 & $82 \%$ \\
\hline 44 & U07182.1 & 0.0 & $\begin{array}{l}\text { Mesocricetus } \\
\text { auratus }\end{array}$ & $\begin{array}{l}\text { Mesocricetus auratus tumor protein } \\
\text { p53 (TP53), mRNA }\end{array}$ & 1044 & $81 \%$ \\
\hline 45 & AJ009673.1 & $\mathbf{0 . 0}$ & Cavia porcellus & $\begin{array}{l}\text { Cavia porcellus tumor protein p53 } \\
\text { (TP53), mRNA }\end{array}$ & 1116 & $79 \%$ \\
\hline 46 & $\begin{array}{l}\text { NM } \\
001009294.1\end{array}$ & 0.0 & Felis catus & $\begin{array}{l}\text { Felis catus tumor protein p53, } \\
\text { mRNA }\end{array}$ & 1120 & $79 \%$ \\
\hline
\end{tabular}

BLAST, basic local alignment search tool; cds, coding sequence; mRNA, messenger ribonucleic acid; TP53, tumor protein. 
Figure 1:-Phylogenetic tree to estimate evolutionary relationships of TP53 gene in different species*

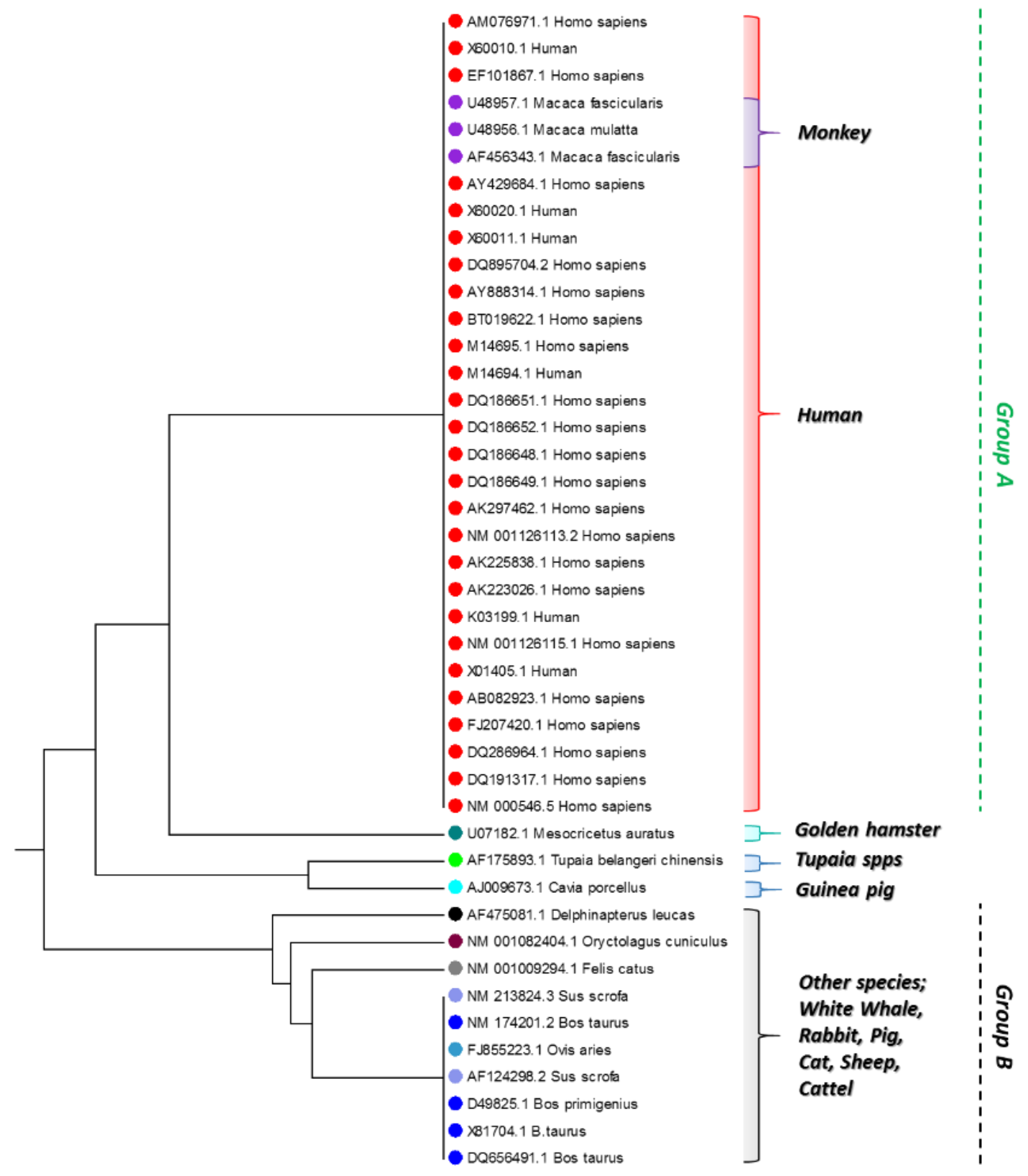

TP53, tumor protein 53.

The evolutionary history was inferred using the UPGMA method. 
Figure 2:-Phylogenetic tree to understand evolutionary distance of TP53 gene in different species*

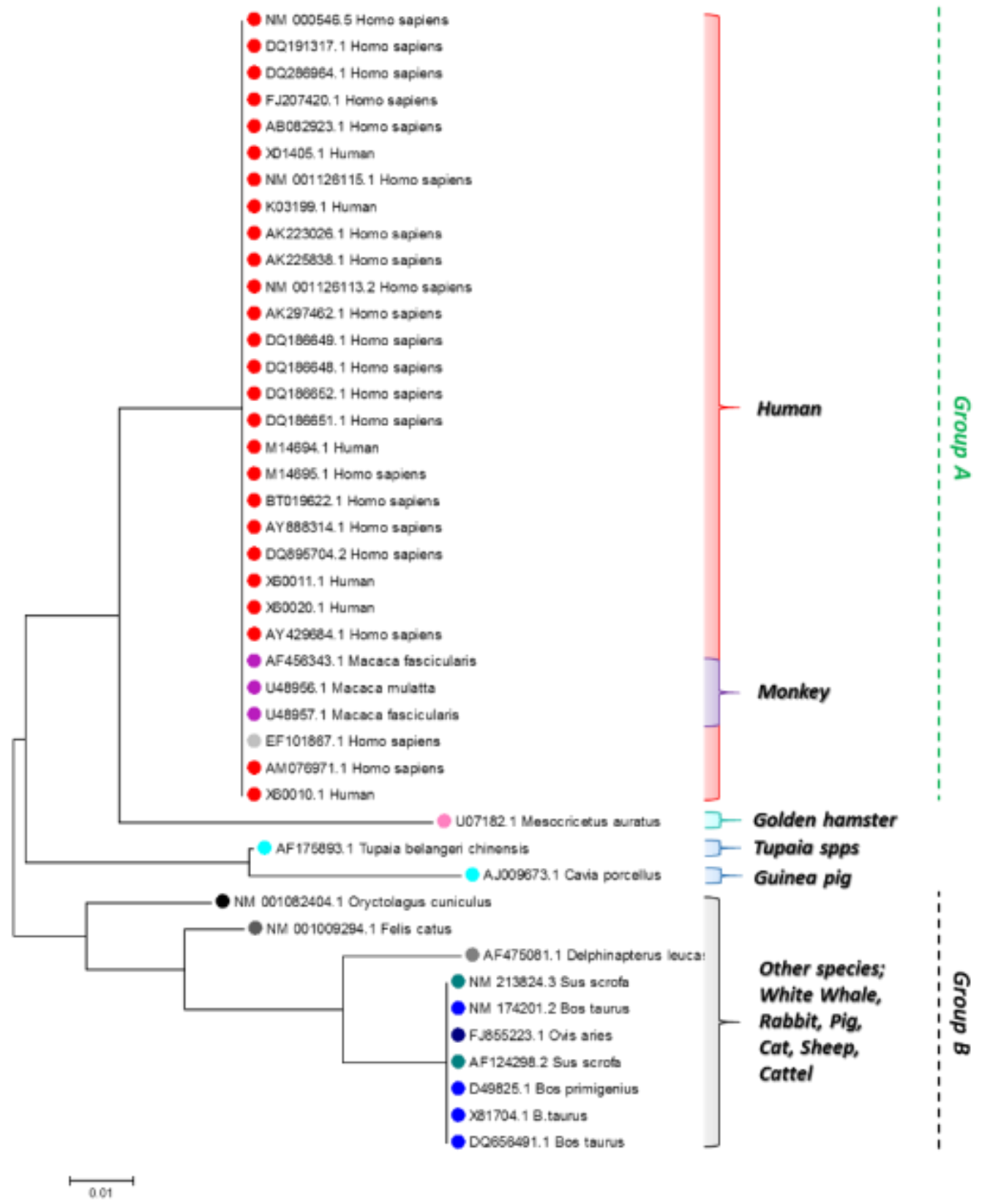

TP53, tumor protein 53.

The evolutionary history was inferred using the UPGMA method.

\section{Results and Discussion:-}

Sequence retrieval:-

Homo sapiens TP53, mRNA, complete cds sequence were retrieved from the NCBI in FASTA format. The sequence of the gene, complete cds (AB082923.1) is presented in Table 1.

\section{Local sequence alignment:-}

The Homo sapiens TP53, mRNA, complete cds sequence was retrieved from the NCBI (https://www.ncbi.nlm.nih.gov/nuccore) in FASTA format, with accession number AB082923.1 (Table 1). Homo sapiens TP53, mRNA, complete cds sequence was studied for its similarity patterns and BLAST was therefore 
performed by feeding the data of sequence into the online NCBI BLAST tool (https://blast.ncbi.nlm.nih.gov/Blast.cgi).

After performing BLAST, the NCBI BLAST tool produced BLAST table (list of the aligned sequence) showing the accession numbers, percent similarity, e-value, etc (Table 2). The sequences having lowest e-value were more closely related while the difference in e-value shows the dissimilarity among them. It is clear from the results that Homo sapiens mRNA for p53, complete cds (BC003596.1), Homo sapiens p53 protein mRNA, complete cd (AF307851.1), Homo sapiens TP53, transcript variant 2, mRNA (NM 001126112.2), Homo sapiens processed transcript p53-mRNA (HG975427.1), Homo sapiens TP53, transcript variant 1, mRNA (NM 000546.5), Homo sapiens p53 protein mRNA, complete cds, alternatively spliced (DQ191317.1), Homo sapiens p53 protein mRNA, complete cds, alternative spliced (DQ191317.1), Homo sapiens mutant p53 mRNA, complete cds (FJ207420.1), Homo sapiens cell-line HCT (JN214348.1), Homo sapiens tumor suppressor TP53 mRNA, complete cds, alternative spliced (JN900492.1), Homo sapiens TP53, transcript variant 8, mRNA (NM 001126118.1), are human p53 gene which were $99 \%$ identical with Homo sapiens TP53, mRNA, complete cds (AB082923.1) sequence.

Homo sapiens TP53, transcript variant 1,2,8, mRNA was 99\% identical with Homo sapiens TP p53, mRNA, complete cds (AB082923.1) sequence, while Cavia porcellus TP53, mRNA (AJ009673.1) and Felis catus TP53, mRNA (NM 001009294.1) were the most dissimilar sequences with $79 \%$ identity (Table 2).

\section{Phylogenetic analysis:-}

In the phylogenetic analysis, alignment of nucleotide or amino acid sequences is a major consideration, particularly in studies of genes from divergent taxa (e.g. human). It seems obvious to state that the phylogenetic analysis of sequences begins with the appropriate alignment of the data themselves, yet alignment remains one of the most difficult and poorly understood facets of molecular data analysis. Alignment of the genomic sequences is required to analyze the phylogenetic tree. Phylogenetic analysis often includes the search for evidence of directional selection in molecular evolution (Hsu et al., 2005; Hofmann et al., 2003). Evolution of the TP53 was studied in different organisms and adaptive changes were in the sequences. The phylogenetic analysis of the p53 gene dataset resulted in a tree consistent with modern systematic understanding of the relatedness among different species, mainly based on DNA sequences homology. This provides strong support for the quality of our sequences and bioinformatics methods. The posterior probability values at the nodes indicate strong support for the branch splits, providing further support for this tree (demonstrated in Figure 1 and 2).

The phylogenetic tree based on UPGMA and NJ method for human and other species were clustered into the two major clades: with human and monkey species grouped together and other species such as whale, rabbit, pig, cat, sheep and cattle, as expected. In additional, we observed the species of hamster, tupaia and guinea pig made separate lineages. Phylogenetic analysis of Homo sapiens TP53, mRNA sequence was performed through the MEGA7 software using Tamura-Nei algorithm (Tamura et al., 1993). The UPGMA rooted tree diagram of Homo sapiens TP53, transcript mRNA sequences showed different clusters formation. Organism that originated from same ancestors having same e-value and $100 \%$ pair wise identity, are placed in same clusters whereas those which are distant from each other are placed in separate clusters (Figure 1).

The optimal tree with the sum of branch length $=0.24911474$ is shown. The tree was drawn to scale, with branch lengths in the same units as those of the evolutionary distances used to infer the phylogenetic tree. The evolutionary distances were computed using the Maximum Composite Likelihood method and are in the units of the number of base substitutions per site. The analysis involved 43 nucleotide sequences. Codon positions included were $1 \mathrm{st}+2 \mathrm{nd}+3 \mathrm{rd}+$ Noncoding. All positions containing gaps and missing data were eliminated. There was a total of 31 positions in the final dataset. Evolutionary analyses were conducted in MEGA7 (Figure 1).

Our observation based on phylogenetic tree using UPGMA method revealed that the majority of human p53 sequences are lying in the same clusters, as expected. Additionally, Macaca species p53 nucleotide sequences are also grouped with human cluster, represented as Group A. However, the p53 gene sequence from different species such as whale, rabbit, pig, cat, sheep and cattle lie mainly in second cluster, named as Group B. In addition, some species are separated from both groups, these species are as follows: Mesocricetus auratus TP53, mRNA (U07182.1), Tupaia belangeri chinensis TP53 mRNA, complete cds (AF175893.1), and Cavia porcellus TP53, mRNA (AJ009673.1). Observations suggest that human and monkey p53 gene are evolved nearly similar species or 
sharing common ancestor. Results also suggest that Group A members p53 gene may be evolved from Group B or both the species have evolved it from the same ancestor (Figures 1 and 2).

The evolutionary history was inferred using the NJ method. The optimal tree with the sum of branch length = 0.26666605 is shown in Figure 2. The tree was drawn to scale, with branch lengths in the same units as those of the evolutionary distances used to infer the phylogenetic tree. The evolutionary distances were computed using the Maximum Composite Likelihood method and are in the units of the number of base substitutions per site. The analysis involved 43 nucleotide sequences. Codon positions included were $1 \mathrm{st}+2 \mathrm{nd}+3 \mathrm{rd}+$ Noncoding. All positions containing gaps and missing data were eliminated. There was a total of 31 positions in the final dataset. Evolutionary analyses were conducted in MEGA7.

We have also analyzed phylogenetic tree using NJ method to determine the evolutionary distance between the TP53 genes in the different species. The principle of NJ method is to find pairs of operational taxonomic units (OTUs; neighbors) that minimize the total branch length at each stage of clustering of OTUs starting with a star like tree. The branch lengths as well as the topology of a parsimonious tree can quickly be obtained by using this method (Saitou et al., 1987). We have retrieved TP53 gene of selected species human, monkey, Guinea pig, Golden hamster, Tupaia, whale, rabbit, pig, cat, sheep and cattle. NJ tree also indicated similar pattern observed using UPGMA based phylogenetic tree. Results revealed that human and monkey have more similar p53 nucleotide sequence compared to other species. However, these both species p53 nucleotide sequences are distinct to Group B member's p53 sequence, including whale, rabbit, pig, cat, sheep and cattle. Interestingly, p53 gene sequence belongs to the species Mesocricetus auratus (U07182.1), Tupaia belangeri chinensis (AF175893.1), and Cavia porcellus (AJ009673.1) are represented homology between both groups. While Mesocricetus auratus TP53, nucleotide sequence is demonstrated more homology with group A, suggesting that Group A member species and Mesocricetus auratus p53 gene are evolved from common ancestor. Observation also suggest that the TP53 genes of human and monkey encoded appropriate similar protein depicted as Group A in figure 2. However, TP53 gene of group B is variable compare to Group A. Group B cluster indicate homology of TP53 gene in whale, rabbit, pig, cat, sheep and cattle. During the study, our finding showed that, Group A cluster member species had more conserved TP53 gene sequence compare to other species.

The observations based on phylogenetic analysis of TP53 gene using UPGMA and NJ method revealed the relationships and percent similarity of TP53 gene within human and others species. Genetic variation among TP53 found in human beings and other organisms were studied in detail. Phylogenetic analysis and multiple sequence alignment of the Homo sapiens TP53, mRNA, complete cds sequence through various phylogenetic tree were performed which showed its pattern of variations and relationship among different organisms especially with rat, mouse and chimpanzee. Our study demonstrated that positive selection of TP53 gene during the divergence of different species during evolution. It is known that homoiothermy and viviparity first appeared among synapsids. These evolutionary acquirements have made necessary changes in the genetic control of ontogeny, and this, in turn, might have caused adaptive changes in the p53 gene.

The findings from the current study will help in modern research strategies through the manipulation and exploitation of p53, as its pathways are promising and one can predict its extensive clinical to control the regulation of p53 in cancer development and biological use in the future for the human benefit worldwide. Furthermore, this study will allow a better understanding of evolutionary aspect of p53 gene in different species. Further study of p53 superfamily proteins in human and other species will further promote our understanding of not only how functional p53 and their functions have evolved in different species but will also contribute to our understanding of the p53 function and evolutionary history.

\section{Acknowledgements:-}

This study is supported by Noida International University-NIU, Gautam Budh Nagar-201308, Uttar Pradesh, India. We acknowledge our thank to the NIU Management team; Dr. A. K. Singh (Chancellor) Dr. D. K. Singh (Chairman), Dr. V. Singh (Pro-Chancellor) and Prof. Dr. KK Dewan (Vice-Chancellor), Noida International University, for their support and allowing us to work at NIU.

\section{Conflicts of Interest Statement:-}

The authors have no conflict of interests to declare. 


\section{References:-}

1. Campisi J. Senescent cells, tumor suppression, and organismal aging: good citizens, bad neighbors. Cell. 2005 Feb 25;120(4):513-22.

2. Chang C, Simmons DT, Martin MA, Mora PT. Identification and partial characterization of new antigens from simian virus 40-transformed mouse cells. J Virol. 1979 Aug;31(2):463-71.

3. Kumar S, Stecher G, Tamura K. MEGA7: Molecular Evolutionary Genetics Analysis Version 7.0 for Bigger Datasets. Mol Biol Evol. 2016 Jul;33(7):1870-4.

4. Kress M, May E, Cassingena R, May P. Simian virus 40-transformed cells express new species of proteins precipitable by anti-simian virus 40 tumor serum. J Virol. 1979 Aug;31(2):472-83.

5. Lane DP, Crawford LV. T antigen is bound to a host protein in SV40-transformed cells. Nature. 1979 Mar 15;278(5701):261-3.

6. Linzer DI, Levine AJ. Characterization of a 54K dalton cellular SV40 tumor antigen present in SV40transformed cells and uninfected embryonal carcinoma cells. Cell. 1979 May;17(1):43-52.

7. Weisz L, Oren M, Rotter V. Transcription regulation by mutant p53. Oncogene. 2007 Apr 2;26(15):2202-11.

8. Bouaoun L, Sonkin D, Ardin M, Hollstein M, Byrnes G, Zavadil J, Olivier M. TP53 Variations in Human Cancers: New Lessons from the IARC TP53 Database and Genomics Data. Hum Mutat. 2016 Sep;37(9):86576.

9. Chumakov PM. Versatile functions of p53 protein in multicellular organisms. Biochemistry (Mosc). 2007 Dec;72(13):1399-421.

10. Tyner SD, Venkatachalam S, Choi J, Jones S, Ghebranious N, Igelmann H, Lu X, Soron G, Cooper B, Brayton C, Park SH, Thompson T, Karsenty G, Bradley A, Donehower LA. p53 mutant mice that display early ageing-associated phenotypes. Nature. 2002 Jan 3;415(6867):45-53.

11. Matheu A, Maraver A, Klatt P, Flores I, Garcia-Cao I, Borras C, Flores JM, Viña J, Blasco MA, Serrano M. Delayed ageing through damage protection by the Arf/p53 pathway. Nature. 2007 Jul 19;448(7151):375-9.

12. Hofmann J, Renz M, Meyer S, von Haeseler A, Liebert UG. Phylogenetic analysis of rubella virus including new genotype I isolates. Virus Res. 2003 Oct;96(1-2):123-8.

13. Hsu HW, Su HY, Huang PH, Lee BL, Liu HJ. Sequence and phylogenetic analysis of P10- and P17-encoding genes of avian reovirus. Avian Dis. 2005 Mar;49(1):36-42.

14. Saitou N, Nei M. The neighbor-joining method: a new method for reconstructing phylogenetic trees. Mol Biol Evol. 1987 Jul;4(4):406-25.

15. Tamura K, Nei M. Estimation of the number of nucleotide substitutions in the control region of mitochondrial DNA in humans and chimpanzees. Mol Biol Evol. 1993 May;10(3):512-26. 